\title{
Implementation challenges of the mandatory health insurance scheme
}

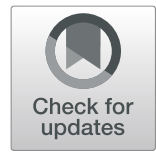

Shaik Sayed Md Rashidul Hossain ${ }^{1 *}$ (D) and Shoaib Mohammad Salman²

\begin{abstract}
Background: Implementation of a mandatory insurance scheme depends on several issues, and among them are regulation, management, and program design which are very crucial. Sometimes a well-designed insurance scheme cannot attract an adequate number of people toward the scheme. Therefore, this study is aimed to explore the implementation challenges of Sajida Foundation's health insurance scheme.

Methods: An exploratory qualitative research design has been applied to explore the challenges that normally exist in regular implementation process. The study population was both field and official level employees who are directly involved in the implementation process of Nirapotta scheme in Karanigoni branch.

Results: Successful implementation of the health insurance scheme of Sajida Foundation is getting constraints by several factors, and among them are lack of dedicated staff for this program, less involvement with community people, inadequate program knowledge dissemination to the people, and not providing incentive for work of Nirapotta are considered as the major challenges of implementation of Nirapotta Scheme. Challenges faced by policy-makers include incoordination with Microfinance Regulatory Authority and not having the latest software for perfect monitoring and evaluation of the Nirapotta program. Apart from this, there are some challenges in implementation which are normally faced in program; some of the most noteworthy findings are incoordination between employees especially in branch level, transient position of Sajida bondhu in the Nirapotta program, and low payment scale compared to other organizations.

Conclusions: Implementation of Nirapotta scheme is getting constraints by multiple factors which can easily be overcome by involving all necessary stakeholders and taking their valuable concern for further development of the scheme to ensure long-term sustainability of the program.
\end{abstract}

Keywords: Health insurance, Implementation challenges, Sajida Foundation, Community-based health insurance, Mandatory health insurance scheme

\section{Introduction}

Health insurance, defined as an insurance system which covers medical expenses which may arise from any uncertain event in life, may cover individual's losses due to accident or injury (Marcinko 2006). There are four main modalities of health insurance: (1) private health insurance, (2) national health insurance, (3) social health insurance, and (4) community health insurance (winter, 2016). Private health insurance could be a mandatory or voluntary insurance system where the revenue is created

\footnotetext{
* Correspondence: shekh.sayed@hotmail.com

'James P. Grant School of Public Health, BRAC University, Dhaka, Bangladesh Full list of author information is available at the end of the article
}

by the premium paid by the insured whereas national health insurance covers the health care costs of all the citizens where the financing source is the national or state government (Schoen, et.al. 2010). The revenue for health insurance is usually funded by tax or fixed budget allocation (McCaffery and E. J 2008). The social health insurance scheme is a mandatory insurance plan where the financing source is the employer or employee from salary or wage (Pan, Xu and Meng, 2016). Community-based health insurance is voluntary health insurance where the premium is paid out of pocket by the insured members and this the pool is generated within a defined community (Dror et al. 2016). In the case of Bangladesh, there is multiple organization 
running community-based health insurance program; among them, Sajida Foundation has its own identity for working for last 17 years (Khan and Ahmed 2013).

Being introduced in 1999, Sajida Foundation (SF) provides microhealth insurance scheme services to a large population of peri-urban and urban areas (Khan and Ahmed 2013). Community-based health insurance (CBHIs) fails to attract a large portion of people especially in the community level and enrollment number is very low because in CBHIs voluntary contribution needed form the members and most of the people can barely afford minimum premium (Liu and Hsiao 2003). For CBHIs, scheme communication and information flow are needed in between the scheme provider and beneficiaries; in most cases, the situation found worst so that the poor members cannot have ultimate benefit from the scheme (Ranson et al. 2007).

The challenges regarding implementation an insurance scheme depends on various factors among the presence of sufficient logistic, payments of premiums on a regular basis, membership board and also regular payment to service providers is very crucial (Agyemang 2013). The designing of a scheme is very crucial; in order to achieve a proper balance between efficiency and equity, it is essential to design scheme with attractive benefit packages is necessary (Purohit 2014). To ensure the sustainability of health care scheme, authorities should review the policy of exemption, contributions rate, particularly, from employees from different informal sector and recruitment standards of organization workforces, continuous exploration for additional funding sources, and re-assess the need of training for employees to ensure competence with others (Fusheini 2016).

\section{Materials and methods}

It was a qualitative exploratory research. The study was conducted in Karanigonj branch office and head office of the Sajida Foundation (SF). Sajida Foundation has a microhealth insurance program and they have been running this operation since 2006 and this operation is exclusively running in only Karanigonj and Narayangonj, the operation in Karanigonj is in larger scale compare to Narayangonj branch that is why branch office of Karanigonj has selected for this study. A convenience sampling technique was applied. The interview was carried out up to reach data saturation point. The interviews were divided into two categories: one was head official level employees, and another one was branch office level staff, and all of them are involved in microfinance and Nirapotta program. An in-depth interview guideline was developed by focusing on the specific objective of the research. Based on the IDI guideline, data was collected through face-to-face interview with employees of the Sajida Foundation.

\section{Results}

Background information about respondents

Table 1 shows basic demographic information of the respondents; about $60 \%$ of respondents were male and the rests of them are female. Their ages range from 21 years to above 40 years of age $90 \%$ of them are Muslims and others are Hindus. Eighty-five percent of respondents work in the branch office of Sajida Foundation in Karanijonj and $15 \%$ working in head office, and they are mainly policy-maker. Twenty percent of them continued their studies up to the secondary level, 30\% completed higher secondary, and 30\% and 20\% completed graduation and post-graduation, respectively.

\section{Responsibility of staffs in different position of the program and their challenges}

Successful implementation of the health insurance scheme of Sajida Foundation is getting constraints by several factors; among one of the major factors that constraints the implementation of the health insurance scheme is lacking dedicated staff for this program; Nirapotta program which covers the health insurance scheme is completely run by the microfinance stuff of Sajida Foundation. Participants from both the head office and branch office reported this issue and considered it one of the major challenges for their program; one of the senior officials specified that

Table 1 Basic demographic information

\begin{tabular}{lll}
\hline Background characteristics & Frequency & Total (\%) \\
\hline Sex & 12 & 60 \\
Male & 8 & 40 \\
Female & & \\
Age group & 4 & 20 \\
$21-25$ & 4 & 20 \\
$26-30$ & 6 & 30 \\
$31-35$ & 3 & 15 \\
$36-40$ & 3 & 15 \\
$\geq 40$ & & \\
Religion & 18 & 90 \\
Islam & 2 & 10 \\
Hindu & & 20 \\
Level of education & 4 & 30 \\
Up to SSC & 6 & 30 \\
HSC & 6 & 20 \\
Graduation & 4 & \\
Post-graduation & 3 & \\
Employment status & 17 & \\
Head office & & \\
Branch office & & \\
\hline
\end{tabular}


"... Branch manager thinks it is an extra burden for them, because they mainly work on Micro finance. So sometimes they don't promote it and sometime they don't brief program information properly" ... ... KII_2_line no_70-72.

Several finding from field-level staff shows that they are quite sincere about their job responsibility, they are performing their task regularly, and their first priority is the microfinance program; one of the staff mentioned that

“... .look after everything in branch; if something happened here I will be the one who will be responsible for this. Our first task is to provide loan and include people into the program through providing loan in every center" ... IDI-5_line no_ 14-16.

\section{Reporting system and existing challenges}

Sajida Foundation have a well-structured reporting and most of the respondents are quite happy with the current reporting system, and the existing reporting system does not require any substantial changes and very few of them suggested that online reporting system requires some technical knowledge, so this kind of operation is not possible to run by untrained professionals. A branch manager asserted that

“... ..We have monthly report it's called MIS, we have software within our computer and it contains a lots of things so one is called program MIS and there is separate MIS for NIRAPOTTA program, in NIRAPOTTA MIS” .....IDI_5_line no_54-57.

Frequent changes of reporting system cause an extra burden for field-level employees, those who have a lack of technical knowledge, one of the Sajide Bondhu stated that

"... they change reporting system frequently, there is no standard reporting system previously we have different form of reporting now they gave different one. If they change system frequently we can barely keep up with those systems of reporting and it creates extra mental presser to us" .... IDI_1_line no_128-131.

Nevertheless, from head office officials, the findings are quite interesting and they are admitting that they have some lacking here and they are trying to go for real-time data collection to ensure good monitoring activities; he mentioned

... .yes we do have some gap in this side, actually we are planning to go for real time data collection if we can do it we can easily monitor the program more efficiently. Now he we needs more time to monitor their activities. ... KII2_line no_97-98.

\section{Training system and challenges}

One of the senior officials mentioned that

“.. Training is regular activities here and it is given to all members according to their needs ... computer skills training, refresher training on MF and also provide training on software”...IDI_8_line no.33-35.

Most of the respondents admitted that the current training system is good for them, and they can equip themselves properly for the program; nonetheless, some employees are not happy with current training procedure, and the interval between two subsequent training is huge. Several branch-level officials asserted that

"from head office we received training it's called Managerial Skills development training, those who join newly they receive it and those who do not receive any training for long time they receive training from there .....IDI_15 line no_65-67.

\section{Supervision system and challenges}

Most of the employees mentioned that existing supervision system is quite well, though field-level employees need more frequent supervision, and one official mentioned that

... SB is not visiting members properly and dropout rate of SB is high. Branch manager could not guide them properly and they can't motivates them properly .... IDI_3_line no_123-126.

However, head office senior officials seem to be amazed after hearing this, and they explained that

“... ..we have 3 different layer of supervision SB's work will be monitor by BM, AC and CL. .... We have different team for NIRAPOTTA they monitor the activities of different program" .... KII_1_line no_55-58.

\section{Enrolment procedure and challenges}

Most of the employees mentioned that clients are satisfied with the current marketing system and policies, but it needs some slight changes to make it more attractive to people. One official stated that

... we have orientation program, we holds this program before we provide any loan and Branch Manager describe the benefits of the program plus, SB 
also holds meeting every day in different centre and she mentioned everything there and if, I personally visit any centre I also discuss everything regarding NIRAPOTTA program ... ... IDI_15_line no_75-77.

Sajida bondhu are visiting community on a regular basis, and they visit every center and check the health status of people and also disseminate the program knowledge, but the demand side findings are very opposite as most of the members have no idea about Nirapotta and they do not know much about the benefits information of Nirapotta program; about $90 \%$ of them has no idea about the health insurance scheme of Sajida Foundation. One of the beneficiaries stated that

“.... I don't know much about Nirapotta , We just take loan from Sajida foundation. They used to give us loan as much as we need. At that moment the loan officer told us if we take loan form Sajida foundation we will get support for health service as well as we will receive money for long time stay in hospital or any kind of major operation ... demand side .... IDI17_line no_7-9".

Although from policy-makers' side, it is clear that they do disseminate program information properly and most senior officials mentioned that

“... .. We have strong marketing policy and for awareness building we go to field. Our BM provide information during the orientation program before disbursement of loan and our SB also visit community every day and we disseminate our knowledge through banner, festoon and poster" .... KII_3_line no_46-49.

\section{Claim management and challenges}

The reimbursement money for each claim is very less which hardly covers $25 \%$ of the total medical costs so the catastrophic health expenditure still exists among the beneficiaries, and a head office personnel mentioned that

“... .in case of claim we are providing only $25 \%$ of total expenditure, So OPP expenditure is more here and which incurring catastrophic expenditure.

Actually our goal is to provide at least $80 \%$ of total expenditure and our target is to achieve UHC" ... KII_2_line no_87-89.

Another major implementation constraint of SF health insurance scheme is the unorganized referral system of patient in hospital. SB normally refer cases to hospital based on the socio-economic condition of the patient and sometimes patient does not get proper support from them as they do not have any dedicated staff for managing referral cases.

One of the SB mentioned that

“..actually we don't have any dedicated person there , but I personally know some people who is working in midford and Dhaka medical college, once I referred any patient there I give them call and asked my patient party to contact with them" ... IDI_13_107-109.

Some other challenges that are commonly faced in program Most of the respondents mentioned that there is incoordination between higher-level employees and fieldlevel employees in field level; one official stated that

“... as our organization is getting bigger and we recruited many staff and they are not that dedicated and their vision is not like us ... ....in field level our worker involving with different work and incoordination between BM, loan office and SB are increases" ... ... IDI-8_99-104.

Head office officials seemingly admitted this issue, and one official also mentioned that

“...... if we can provide an effective incentive to them it might work and from Microcredit program everyone receive incentive except Loan officer but he is directly involve in this NIRAPOTTA program and he did manage all records of claim and other issues ..."KII-2_104-107.

Policy-makers are not providing incentive to all level employees, and the finding shows that because of this, some employees are taking time to proceed files promptly as they think that the workload of Nirapotta is an extra burden for them and they do not properly coordinate with others, which hampers the overall implementation of the Nirapotta scheme. Among all key role players in the overall implementation process, SB plays a crucial role, but they are still not being treated as permanent employees. One SB stated that

“.... sometimes I think, that I works a lot but I am not a permanent members and we can't even tell anyone that we are not permanent employee of SF. So my only recommendation is if they don't increase our salary it's okay for us but if they make our position permanent it will be great mental satisfaction for us" ... IDI-13_140-143.

Most of the employees are satisfied with the salary range and attractive packages but SBs want their post 
permanent so that they can work with their best optimum level, and the implementation of the health insurance scheme will be even more successful. However, the policy-maker makes this point clear and they mentioned the reason behind this issue.

“... Basically in permanent and contractual basis job there is no difference in facility only there is one difference in provident fund and gratuity, because dropout rate is higher there...actually we have plan to make their position permanent but the problem is drop-out rate, dropout rate is very high among the SB"..KII-3_111-113// KII-1_98-99.

Besides those challenges, there are some other challenges which are facing policy-maker among those in coordination with Microfinance Regulatory Authority and not having the latest software for perfect monitoring and evaluation of Nirapotta program, in this regards one of higher officials cited that

“.. ..., We can't design the program by our own style we have to design it according MRA, ... .., Because of MRA regulation doesn't allow it" ... .._KII-1_137-140 // "... we can't run everything by our existing software and we can do our analysis smoothly, we don't have any software for smooth analysis. Regulation and Software is the big challenge ......_KII-1_154-156.

Nevertheless, the findings also show that despite all those existing problems, the health insurance scheme is very popular among all respondents. Out of all 19 programs, Nirapotta program is one of the best programs, and its health insurance scheme makes this program quite unique. By overcoming existing challenges, Sajida Foundation wants to implement this program in large scale, and they also want to run health insurance program as a voluntary program by cooperating with government organization; in this regard, one of the key informants stated that

“... .actually we are planning to tag up with some organization especially with government organization or any cooperative organization. If we can do that we can sustain our program. As we are trying to achieve Universal health coverage ( UHC) so tagging with government organization will helps us to achieve this programs goal to ensure Health for All" ... ..KII2_101-104.

\section{Discussion}

As health insurance scheme is a part of the Nirapotta program which is directly linked with the microfinance program so this program is running by the existing workforce of the microfinance program. Sajida bondhu $(\mathrm{SB})$ are front line workers whose main responsibility is to visit the center and household of loan borrowers and to check their health condition, and apart from this, they also follow up pregnant women and ensure their four ANC checkup. SBs are mainly field-level workers, and they play a major role in the dissemination of program information to the community people. Loan officer or field offices' main task is disbursing and collecting money from the members. In Nirapotta program, they are also responsible for the dissemination of program knowledge as well as they are the one who is involved in the claim settlement process. Every branch office is run by a branch manager, who also visits the field regularly, attends in the courtyard meeting, and provides knowledge about the program. In a branch office, the accounts officer plays a major role as they keep records of all necessary documentation in an organized way including claim management records through claim tools software. The area coordinator looks after five branch offices' activities and cluster leader looks after activities of five area coordinators' activities. Besides those, a community organizer is one separate post that looks after SBs' activities more precisely, visits the field with SB, and is also responsible for the dissemination of program information.

Not having a dedicated staff for Nirapotta program constraints the implementation of health insurance scheme, and this finding is quite similar with the results attained by Ntewusu (2014) who stated that having less number of dedicated staff with inadequate logistic support to run office is one of the major constraints of the implementation of national health insurance scheme.

Every staff has to report regularly to the head office and the duration of reporting is weekly, monthly, and quarterly. However, the reporting system seems to vary from employees to employees and everyone needs to report to their seniors. SBs have to keep record of all of their daily activities in their diary, and it should be submitted to the branch manager. The branch manager reports to area coordinator on a daily, weekly, and monthly basis; contents of the report are mainly microfinance and Nirapotta program. The area coordinator reports to the cluster leader. The reporting system is mainly online-based, and they have particular format for reporting; according to branch manager, the monthly report is called MIS, and they separate MIS from Nirapotta and microcredit program.

Contents of Nirapotta MIS are mainly total number of claims settled and number of people applied for claim, and from them, how many are rejected, etc. The gap between the branch office and head office arises due to major or minor information gap during the reporting system.

Frequent changes in rules and regulation also constraints the implementation process of the program, and studies from Adam Fusheini is very consistent with 
finding regarding reporting issues. Fusheini (2016) concluded that rapid changes in rules and policy-making decision is considered as one of the core challenges in the implementation process.

The employees training vary according to their level, grade and position they holds; based on the needs of the staff head office offers training accordingly. Before promoting any employee to a higher post, they called that batch from different types of trainings including managerial skills training and computer training for their employees. Since SBs check blood pressure, blood sugar, and perform diabetic test that is why SBs are asked for 15 days mandatory training on those issues. To overcome all those technical and other professional challenges, Sajida Foundation train their employees regularly; however, they have different types of training facility for different role players in the implementation process.

Successful trained professionals play a vital role implementation process and to ensure maximum output form them employees Sajida Foundation has a strong supervision system. SBs' works are mainly supervised by branch officer, community organizer, and field officer. Branch manager supervise each and every personal work in the branch office including field officer, and accounts officers' work is mainly supervise by a finance supervisor. Area coordinator supervise activities of five branch managers, and activities of five area coordinators are supervised by cluster leader and their overall activities of Nirapotta program is supervised by different team from head office in regular interval. SBs are the front line worker, and they play a vital role in implementation of the program; they are also accepted by all community members, and they have earned trust from all level people from the community, so any message from them is very crucial and their messages have an impact on implementation of both Nirapotta program as well as microfinance program.

As it is a mandatory product of microcredit program, whoever borrows or loans from SF will be automatically under this scheme. However, a successful enrolment procedure depends on several factors like vigorous marketing system, frequent communication with community people, and dissemination of the program knowledge in most convenient way. Frequent communication with community people is needed for successful implementation of any program, Sajida Foundation needs to focus more to supervise the activities of field-level staff; otherwise, there will be a gap between supply side and demand side, and the enrolment will be very less in the particular program. Enrolling people in the health insurance program is quite time-consuming and successful enrolment procedure depends on several factors like marketing system, involvement with potential customers, and dissemination of program benefits information to people. In this regard, Sajida Foundation is not performing the same in all aspects.

Despite having some degree of lacking, existing marketing policy is going well and vigorous activity of different role players making health insurance program accessible to community people; this finding is quite similar with Ntewusu (2014) who mentioned information about scheme only can spread to people through the concrete commitment from all level of stakeholder, and it also depends on their frequent mobilization to community with vigorous promotional strategies of their products.

Some other challenges of enrollment procedure are making people understand about the health insurance knowledge of Nirapotta program, and people are still not clear about the premium rate. All they do care about is the load which they will receive from Sajida Foundation for business purposes. Most of the branch-level officials admitted that they do have a gap regarding the dissemination of program knowledge, and it is one of the major implementation challenges of the health insurance scheme. For instance, the findings from other studies (Ntewusu 2014) demonstrated that knowledge gap about the programs' benefits among community people has detrimental effects on the overall implementation of a scheme.

Regular claim management has an organized way for members to submit their hospital discharge certificate and other necessary documents to the field office and sometimes to the Sajida Bondhu; they check the authenticity of the claim and afterward they refer it to the BM and BM forward it to a doctor to check whether the claim is authentic or not, and sometimes field officer visit the hospital to check whether that patient was really admitted there or not. After those all procedure, BM approve or reject a claim; if a branch manager cannot understand any case, then he refers it to the area coordinator, and if the area coordinator fails to identify the category, they refer it the cluster leader if he cannot manage it then he refers it to the head office. Eighty percent of the claims are managed in branch office by the branch manager and area coordinator. The implementation process of health insurance scheme is a further constraint due to challenges in claim management procedure. Regarding claim settlement time, half of the respondents seem to be okay with that but the major challenges are related to documentation process and referral of claim to a higher authority which are very time-consuming; it takes about more than a month if a claim case is referred to the head office. Successful claim settlement requires all necessary documents including hospital discharge certificate; in most cases, people use a different name, and sometimes they do false claims and identification of false claims is another constraint for health insurance program.

In some cases, the entrepreneur loan borrower does not even claim, because the reimbursed money is very less which is a much-neglected amount compared to 
their total cost; even the existing loan borrower can hardly prevent the catastrophic health expenditure with current reimburse. So lesser reimbursed money for claim and longer duration in claim settlement are some of the constraints of health insurance scheme of Sajida Foundation; this finding is also consistent with Witter S. and Garshong B. (2009) who stated that even insured person has to pay for different items which should be under the coverage of insurance scheme, and sometimes those expenditure leads to excess out of pocket expenditure and incurring them to catastrophic health expenditure. Some other challenges in claim management is referring of claim to a higher authority which takes extra time, and sometimes, if a branch manager fails to settle claim in branch office, then they refer it to area coordinator; about $80 \%$ of claims are settled in branch office with the help of $\mathrm{BM}$ and $\mathrm{AC}$, and if they cannot figure out, then they refer to cluster leader and afterwards they refer it to head office, and this entire process takes about 2 months.

People are not satisfied with the existing referring system, and they have bitter experience about this system, and most of the time, they get harassed in some of the referred facilities; this is also considered as an implementation challenge of health insurance as well as that of Nirapotta scheme. These findings are also consistent with literature which was published by Ghana Health Service (2007) referring patient to tertiary level hospital leads to higher cost and if the reimburse money is less compared to hospital cost, people seem to have negative thought on health insurance, which ultimately affects the implementation of the health insurance in national level.

Apart from this, there are some challenges in implementation which are normally faced in the program; some of the most noteworthy findings are in coordination between employees especially in branch-level, transient position of Sajida bondhu in the Nirapotta program, and low payment scale compared to other organization. Lack of coordination among senior and junior level employees is one of the hindrances of implementation of Nirapotta program, and several findings show that the coordination between SB and loan office is not up to the mark, besides branch managers were not able to motivate SB.

This incoordination ultimately leads to the communication gap because this normal process of implementation is getting hampered; this finding is quite similar with the study of Ntewusu (2014) who stated that lack of coordination among all role players in implementation process is a major obstacle for a health insurance scheme.

This finding is similar with the study of Egonmwan (1971) who stated that for the successful implementation of any health insurance program, the responsibility of government is very crucial, and in the long run, tagging up with government to ensure superior sustainability is important.

\section{Conclusion}

Sajida Foundation is running several programs, and among all existing programs, the Nirapotta program is considered as one of the best program. The study revealed that implementation of this scheme is getting constraints by several factors which can easily be overcome by involving all necessary stakeholders and taking their valuable concern for further development of the program to ensure the longterm sustainability of the program. By creating awareness about the program benefits among the community people especially those who are involved in informal sector and paying more attention to the poor group people will help to increase the coverage of the program and it will help to grab more potential members in the scheme. More research and academic approach should be emphasized on addressing and studying a gradual approach of this kind of scheme; where the focus should be given more on providing health insurance particularly to poor people. This can easily be achieved by instituting collaborative links with different stakeholders like government, NGOs, and other institution. The study has only been conducted in Karanigonj, but Sajida Foundation has a similar kind of operation in Narayangonj. Findings would have been different if we could include Narayangonj area also.

\section{Abbreviations \\ AC: Area coordinator; ANC: Antenatal check-up; BM: Branch manager; CBHI: Community-based health insurance; CL: Cluster leader; IDI: In-depth interviews; KIl: Key informant interviews; MF: Microfinance; MIS: Management information system; MRA: Microfinance Regulatory Authority; NGO: Non- government organization; OPP: Out of pocket payment; SB: Sajide bondhu; SF: Sajida Foundation}

\section{Authors' contributions}

Hossain, S. S. M. designed and conduct the study as well as reviewed whole manuscript. Salman, S. M. prepared data matrix and other froms of analysis. Both authors read and approved the final manuscript.

\section{Funding}

Not applicable.

Availability of data and materials

Not applicable.

Ethics approval and consent to participate

Consent was taken from the respondent before conducting any interview. A structured consent form was developed and sign was taken from each participant.

Consent for publication

Not applicable.

Competing interests

The authors declare that they have no competing interests.

Author details

${ }^{1}$ James P. Grant School of Public Health, BRAC University, Dhaka, Bangladesh.

${ }^{2}$ Department of Public Administration, University of Dhaka, Dhaka,

Bangladesh. 
Received: 27 June 2019 Accepted: 12 September 2019

Published online: 24 October 2019

\section{References}

Agyemang KK (2013) Prospects and challenges of implementing a sustainable National Health Insurance Scheme: the case of the Cape Coast Metropolis, Ghana. Int Knowledge Sharing Platform 3:12 Retrieved from https://www. researchgate.net/publication/271704247

Dror DM, Hossain SS, Majumdar A, Koehlmoos TLP, John D, Panda PK (2016) What factors affect voluntary uptake of community-based health insurance schemes in low-and middle-income countries? A systematic review and meta-analysis. PLoS One 11(8):e0160479

Egonmwan, J., A. 1971. Public Policy Analysis: Concepts and Applications, Benin City: S.M.O. Aka and Brothers Press.

Fusheini A (2016) The politico-economic challenges of Ghana's National Health Insurance Scheme Implementation. Int J Health Policy Manag 5(9):543-552. https://doi.org/10.15171/ijhpm.2016.47

Ghana Health Service. (2007). Annual Report

Khan JA, Ahmed S (2013) Impact of educational intervention on willingness-topay for health insurance: a study of informal sector workers in urban Bangladesh. Heal Econ Rev 3(1):1

Liu Y, Hsiao WC (2003) For the people, by the people: community financing of healthcare in developing countries. Harvard Health Policy Rev 4:102-111

Marcinko, D. E [edited](2006) Dictionary of health insurance and managed care. New York: Springer Publishing Company Inc

McCaffery, \& E. J (2008) Fair not flat: how to make the tax system better and simpler. University of Chicago Press

Ntewusu AD (2014) Implementation of the district-wide mutual health insurance scheme in Ga west municipality. Lambert Acad Publishing 1:124

Pan, X., Xu, J., \& Meng, Q. (2016). Integrating social health insurance systems in China. The Lancet. 387, 10025, P1274-1275. Retrieve from https://doi.org/10. 1016/50140-6736(16)30021-6

Purohit, B. (2014) Community based health Insurance in India: prospects and challenges. Sci Res. Retrieve from https://doi.org/10.4236/health.2014.611152

Ranson, M.K. Sinha, T., Chatteriee, M., Gandhi, F., Jayswal, R., Patel, F., Morris, S.S. \& Mills, A.J. (2007) Equitable utilization of Indian community based health insurance scheme among its rural membership: cluster randomized controlled trial. Brit Med J, 334, 1282-12783. Retrieve from https://doi.org/10. 1136/bmi.39192.719583.AE

Schoen, C., Osborn, R., Squires, D., Doty, M., Pierson, R., \& Applebaum. S. (2010). How Health Insurance Design Affects Access To Care And Costs, By Income, In Eleven Countries. Health Affairs.29, 12.

Witter, S., Garshong, B. (2009). Something old or something new? Social health insurance in Ghana. BMC International Health and Human Rights.28;9:20. Retrieve from 1472-698X-9-20. https://doi.org/10.1186/1472-698X-9-20.

\section{Publisher's Note}

Springer Nature remains neutral with regard to jurisdictional claims in published maps and institutional affiliations.

\section{Submit your manuscript to a SpringerOpen ${ }^{\circ}$ journal and benefit from:}

- Convenient online submission

- Rigorous peer review

- Open access: articles freely available online

- High visibility within the field

- Retaining the copyright to your article

Submit your next manuscript at $\boldsymbol{\nabla}$ springeropen.com 